\title{
The impact of street cleaning on particulate matter air concentrations: a case study of a street canyon in Krakow (Poland)
}

\author{
Marek Bogacki ${ }^{1,{ }^{*}}$, Robert Oleniacz ${ }^{1}$, Mateusz Rzeszutek ${ }^{1}$, Adriana Szulecka ${ }^{1}$ and Marian \\ Mazur $^{1}$ \\ ${ }^{1}$ AGH University of Science and Technology, Faculty of Mining Surveying and Environmental \\ Engineering, Department of Environmental Management and Protection, Krakow, Poland
}

\begin{abstract}
The paper presents the impact of the cleaning of a dual carriageway located in a street canyon in Krakow (Southern Poland) on the levels of the $\mathrm{PM}_{10}$ and $\mathrm{PM}_{2.5}$ air concentrations. For this purpose, representative dust samples from the analysed street were collected corresponding to the street cleaning situation, the re-entrained road dust $\mathrm{PM}_{10}$ and $\mathrm{PM}_{2.5}$ emissions were estimated in accordance with the U.S. EPA guidelines, and the particulate matter atmospheric dispersion modelling was carried out using the CALINE4 model for a selected episode of street cleaning. The modelling results were compared with the measurement results of the $\mathrm{PM}_{10}$ and $\mathrm{PM}_{2.5}$ air concentrations obtained from the air quality monitoring station (traffic type) located in the middle of this street canyon. The results of the air dispersion modelling in the canyon zone confirmed the strong impact of street cleaning on the temporary (1-hour) $\mathrm{PM}_{10}$ concentrations in the direct vicinity of the cleaned section depending on meteorological conditions. During the cleaning episode, no significant increase in the $\mathrm{PM}_{2.5}$ concentration in the air was observed.
\end{abstract}

\section{Introduction}

The main source of $\mathrm{PM}_{10}$ and $\mathrm{PM}_{2.5}$ emission into the air from roads are internal combustion engines and dust deposited on the road surface, which can be resuspended due to an occurrence of wind gusts and turbulence caused by moving vehicles [1]. Dust material deposited on the road may be of natural origins (e.g.: aeolian erosion, the inflow of the Sahara sand, sea salt, pollen from trees) or anthropogenic. The sources of the latter may be, among others, the wearing processes of tyres or the road surface, brake linings and road markings, the dry and wet deposition of industrial or municipal dust, and winter road maintenance agents [2-8]. The fractional and chemical composition of the dust material deposited on roads is determined geographically, environmentally and anthropogenically [1].

For years, studies have been conducted to assess the impact of dust emissions from vehicles (exhaust) and from roads (non-exhaust) on air quality using, among others, the pollutant dispersion models such as: OSPM [3, 9, 10], CALINE4 [11], CMAQ [3],

* Corresponding author: bogacki@agh.edu.pl 
CHIMERE [4], CMB [12], AERMOD [12]. In the studies, an estimation of the secondary dust emissions from roads was carried out using the most common emission factor method developed by the U.S. EPA [13, 14], sometimes after small [11] or significant modification [15]. To parameterize the process of secondary dust emissions from roads, other emission models were developed, an example of which can be the NORTRIP model. In this model, the dust emissions from roads are estimated based on the mass and energy balance equation, taking into account all the most importants processes of road dust emissions [16]. The results of research carried out in this field indicate, that consideration of the secondary dust emission dispersion in the calculations significantly improves the prognostic effectiveness of the models $[3,4,10-12]$. Numerous researchers believe, that even better agreement between the calculated and observed values of the particulate matter concentrations in the air near roads can be achieved by a more accurate description of the background concentration levels, e.g. by taking into account the local, regional and global inflows of the dust over the analysed area (for example the inflow of the sand from Sahara or other deserts) [3, 4, 17].

Street cleaning is an important facet of any solid waste management system, and is directly related to public education and behaviour. The primary aim of road sweeping is to improve the aesthetic appearance of an urban environment by removing street debris, litter and dirt. Factors that are likely to affect the efficacy of road sweeping in reducing the $\mathrm{PM}_{10}$ concentrations include the following: road dust loading, the sweeper's efficiency in removing $\mathrm{PM}_{10}$ from the road surface, the ability of the machine to retain the particles, road surface, the portion of the road that is swept, the frequency of sweeping and the length of road swept. The sweeper exhaust emissions are unlikely to be significant in the context of the 24-hour mean $\mathrm{PM}_{10}$ limit value [18].

In recent years there has been a great amount of research to determine the most effective means of controlling the non-exhaust emissions. A number of these studies have investigated road dust loading of various sizes, and the efficacy of road sweepers to remove it $[15,18$ 20]. The effectiveness of road sweepers in removing the contaminants from roads depends, among other things, on the type of sweeper. There are three general types of road sweepers in use in Europe: mechanical sweepers, vacuum sweepers and regenerative-air vacuum sweepers; with the latter not being common in Europe. Presently, due to the growing public awareness about the health risks involved with poor air quality, the key parameter for sweepers assessment is their ability to isolate $\mathrm{PM}_{10}$. Traditional mechanical sweepers are unable to accomplish this, which is due to their simple technical design, to retain very fine particles, including $\mathrm{PM}_{10}$. Sweeper manufacturers have therefore been obliged by customers and governmental organizations in different countries to certify their products in terms of their $\mathrm{PM}_{10}$ particulate matter retention efficacy [18]. The certification tests of modern road sweepers (equipped with, among others, high-performance fabric filters) indicate that the best sweepers can suppress from 48 to $100 \%$ of $\mathrm{PM}_{10}$ entering the sweeper [18].

Amato et al. [2] have reviewed the effectiveness of road sweeping and washing, as well as the application of dust suppressants. With regard to the impact of street sweeping on ambient PM concentrations, Amato et al. reviewed 15 studies and concluded that it was ineffective in the short term. Some sweepers produce a visible dust cloud from their brooms or the air discharged from their collection hopper, and in some studies the $\mathrm{PM}_{10}$ concentrations increased [21]. When sweeping is combined with water flushing there were more encouraging results. This could be due to the wetting of the road surface and not from actually cleaning the road [18]. In two studies the improvement was definitely attributed to sweeping/washing operations which yielded efficiencies of up to $30 \%$ and $24 \%$ respectively. However these showed that the benefits were short-lived, lasting no more than 3 to 4 hours for total suspended particulate (TSP) and 2 to 3 hours for $\mathrm{PM}_{10}$ [20]. In two other tests in Germany and Spain, a meteorological dilution of pollutants did not permit definitively quantifying the benefit, even if a rough approximation estimated it around $7-10 \%$ of the $\mathrm{PM}_{10}$ 
levels [22]. The final two studies found that the $\mathrm{PM}_{10}$ reductions were too small when compared to the measurement uncertainty. The authors noted that the impact of sweeping/washing roads is likely to be small as road dust is only one source of PM in an urban area, and the atmosphere is continually mixed. Research on the effectiveness of only washing roads in Germany and Sweden indicated a limited or no effect on $\mathrm{PM}_{10}$ levels [2].

Synthetic literature analysis on the state of knowledge regarding secondary road dust emission sources along with a review of counteraction methods revealed the complexity of this issue. So far, the results of research studying the impact of the road dust emissions on air quality, and in particular the results of research on the impact of various street cleaning technology on the $\mathrm{PM}_{10}$ concentration levels are extremely divergent, and sometimes even contradictory. Researchers have not yet been able to clearly determine the scale of the decrease/increase in the $\mathrm{PM}_{10}$ concentration in the air due to the mechanical cleaning and washing of the streets.

Presented in the paper, both empirical and computational studies were aimed at enriching the still insufficient state of knowledge on the impact of mechanical street cleaning on the $\mathrm{PM}_{10}$ and $\mathrm{PM}_{2.5}$ 1-hour concentrations in the air.

\section{Research methodology}

The aim of the study was to assess the effect of street cleaning on the $\mathrm{PM}_{10}$ and $\mathrm{PM}_{2.5}$ particulate matter concentrations in the air. In the study, an episode of intensive street cleaning, which took place in April 2015 over the night of the $15^{\text {th }}$ to $16^{\text {th }}$, between 24:00 and 1:00 on Krasinski avenue in Krakow (Southern Poland). Krasinski avenue is located in the city centre, in a street canyon with a width of $48 \mathrm{~m}$ and an average building height of $20 \mathrm{~m}$. The street has two asphalt roadways with three lanes each. The roadways are separated by a green belt with a width of $17 \mathrm{~m}$. Krasinski avenue is one of the streets in Krakow with the most intensive traffic. The average daily traffic volume of vehicles during work days is about $18000 \mathrm{veh} \cdot$ day $^{-1}$, on Saturdays about $17000 \mathrm{veh} \cdot$ day $^{-1}$, and on Sundays and holidays around $14000 \mathrm{veh} \cdot$ day $^{-1}$. The maximum traffic volume on work days during the afternoon rush hours may reach a level of $5000 \mathrm{veh} \cdot \mathrm{h}^{-1}$ [23]. An automatic air quality monitoring station is located in the green belt between the two roadways, which during the conducted studies was used to verify the modelling calculations results.

The research was carried out in two stages. The first stage involved the collection of three representative samples of the dust material at night from the examined section of the roadway and the estimation, based on the results of the analysis, the $\mathrm{PM}_{10}$ and $\mathrm{PM}_{2.5}$ emission factors for the analysed mechanical street sweeping process. During the second stage of the study, the impact of the estimated emission rates on the $\mathrm{PM}_{10}$ and $\mathrm{PM}_{2.5}$ concentrations in the air of the street canyon was modelled using the CALINE4 diffusion model for linear sources [24], taking into account the meteorological conditions occurring during the considered street cleaning episode.

As part of the first stage of the research, three samples of the dust material were collected from the analysed street section according to the U.S. EPA methodology described in [13, 14]. Due to the specificity of the research, a small modification was introduced to the methodology, involving the sampling of the dust material not only from the asphalt surface, but also from the area directly at the curb of the roadway, where usually the largest amount of deposited dust is accumulated. The collected dust samples were subjected to granulometric analysis. Determination of the granulometric composition was conducted using a sieving method (analysis of the fractions above $0.071 \mathrm{~mm}$ ) and a laser diffraction method using the Malvern Instruments Mastersizer 2000 particle size analyser (analysis of the fine fractions up to $0.00002 \mathrm{~mm}$ ). A detailed description of the dust material sampling and the methodology of its fractional composition measurement were presented for the analysed experiment in the 
work [11]. The particulate matter emission rates during the mechanical sweeping process on Krasinski avenue was determined in accordance with U.S. EPA guidelines [13].

Calculations of the $\mathrm{PM}_{10}$ and $\mathrm{PM}_{2.5}$ in the air were carried out at receptors located on the line with a length of $45.5 \mathrm{~m}$ perpendicular to the axis of Krasinski avenue and at the location of an automatic air quality monitoring station. The CALINE4 computational model apart from the general data, geometry and the characteristics of the substitute emission source, the location of the receptors and the emission description was provided with the actual meteorological data characterising the examined episode, such as: wind speed $\left[\mathrm{ms}^{-1}\right]$, wind direction $\left[{ }^{\circ}\right]$, standard deviation of the wind direction $\left[^{\circ}\right]$ (assumed constant at $10^{\circ}$ ), atmosphere stability class (determined according to the Smith stability nomogram), height of the mixing layer $[\mathrm{m}]$ and ambient temperature $\left[{ }^{\circ} \mathrm{C}\right]$.

\section{Results and discussion}

Physical tests of the dust samples collected from the street revealed their low relative humidity (average value: $0.364 \%$ ). In the analysed dust the coarse fractions with a particle size of 75-500 $\mu \mathrm{m}$ and more than $500 \mu \mathrm{m}$ dominated. On average, they constituted 66.3 and $30.5 \%$ of the dust samples' mass, respectively. The share of fine fractions (that can be resuspended from the road) with a particle diameter below $75 \mu \mathrm{m}$ accounted for $3.2 \%$. The specific parameter sL (silt Loading) determined based on the collected samples and characterising the dust loading (particle sizes up to $75 \mu \mathrm{m}$ ) on the road surface, was equal to $\mathrm{sL}=0.38 \mathrm{~g} \cdot \mathrm{m}^{-2}$. Subsequently, the calculated value of the $\mathrm{sL}$ parameter was used to estimate the value of the $\mathrm{PM}_{10}$ and $\mathrm{PM}_{2.5}$ emission factors, which for the investigated road reached respectively: 0.45 and $0.12 \mathrm{~g} \cdot \mathrm{km}^{-1} \cdot \mathrm{veh}^{-1}$. Based on the calculated emission factors and the actual traffic parameters on the analysed road section during rush hour, the actual $\mathrm{PM}_{10}$ and $\mathrm{PM}_{2.5}$ emission values of 2.14 and $0.59 \mathrm{~kg} \cdot \mathrm{h}^{-1}$, respectively, were calculated.

In Table 1 the actual meteorological parameter values occurring during the examined episode are presented, i.e.: wind speed (WS), wind direction (WD), temperature (T), barometric pressure $(\mathrm{Bp})$, air humidity $(\mathrm{H})$, atmospheric precipitation $(\mathrm{P})$. Slightly stable conditions of the atmosphere persisted during the street cleaning (PGT 5).

Table 1. Selected meteorological parameters occurring during the analysed period.

\begin{tabular}{|c|c|c|c|c|c|c|}
\hline Data & $\mathbf{W S}\left[\mathbf{m} \cdot \mathbf{s}^{-1}\right]$ & WD [ [ $\left.{ }^{\circ}\right]$ & $\mathbf{T}\left[{ }^{\circ} \mathbf{C}\right]$ & $\mathrm{Bp}[\mathrm{hPa}]$ & H [\%] & $\mathbf{P}\left[\mathbf{m m} \cdot \mathbf{h}^{-1}\right]$ \\
\hline 2015-04-15 22:00 & 2.34 & 276 & 16.9 & 985.5 & 38.9 & 0 \\
\hline 2015-04-15 23:00 & 1.32 & 310 & 15.3 & 985.3 & 43.4 & 0 \\
\hline 2015-04-15 24:00 & 1.10 & 289 & 14.4 & 985.1 & 46.4 & 0 \\
\hline 2015-04-16 01:00 & 1.00 & 322 & 13.8 & 984.6 & 48.2 & 0 \\
\hline 2015-04-16 02:00 & 0.41 & 192 & 12.4 & 984.3 & 52.2 & 0 \\
\hline 2015-04-16 03:00 & 0.61 & 204 & 11.5 & 984.0 & 54.5 & 0 \\
\hline
\end{tabular}

As results from the information showed in Table 1, around 1:00 on 15.04.2015 and during the street cleaning episode, the wind blew parallel to the street canyon at a small speed of about $1 \mathrm{~m} \cdot \mathrm{s}^{-1}$, which caused a slow and uniformly distributed transport of the dust resuspended from the road towards the south in the entire street canyon. The lack of precipitation, a relatively small air humidity (around 48\%) and air temperature considerably above the dew point temperature - all these factors were conducive to the resuspension of fine particles in the air during the mechanical street sweeping process with a sweeper not equipped with a $\mathrm{PM}_{10}$ reduction system. Measured on 16.04.2015 during the hours of 24:00- 
01:00 at the air quality station at Krasinski avenue the 1-hour averaged concentration of $\mathrm{PM}_{10}$ and $\mathrm{PM}_{2.5}$ was 262 and $66 \mu \mathrm{g} \cdot \mathrm{m}^{-3}$, respectively; while one hour earlier it reached 121 and 54 $\mu \mathrm{g} \cdot \mathrm{m}^{-3}$, respectively. In the period from $23: 00$ on 15.04.2015 to $01: 00$ on 16.04 .2015 , there was an increase in the 1-hour concentration of $\mathrm{PM}_{10}$ and $\mathrm{PM}_{2.5}$ by 141 and $12 \mu \mathrm{g} \cdot \mathrm{m}^{-3}$, respectively. Meteorological parameters presented in Table 1 indicate that very similar conditions persisted during the street cleaning period and one hour before. This fact allows, with a high probability, to conclude that the abovementioned increase of $\mathrm{PM}_{10}$ and $\mathrm{PM}_{2.5}$ concentrations was predominantly caused by the mechanical sweeping process on Krasinski avenue. The subsequent street washing process did not influence the levels of the measured concentrations. The variability of the $\mathrm{PM}_{10}$ and $\mathrm{PM}_{2.5}$ particulate matter concentrations measured at the air quality monitoring station (Krasinski avenue) in the analysed period is presented in Fig. 1.

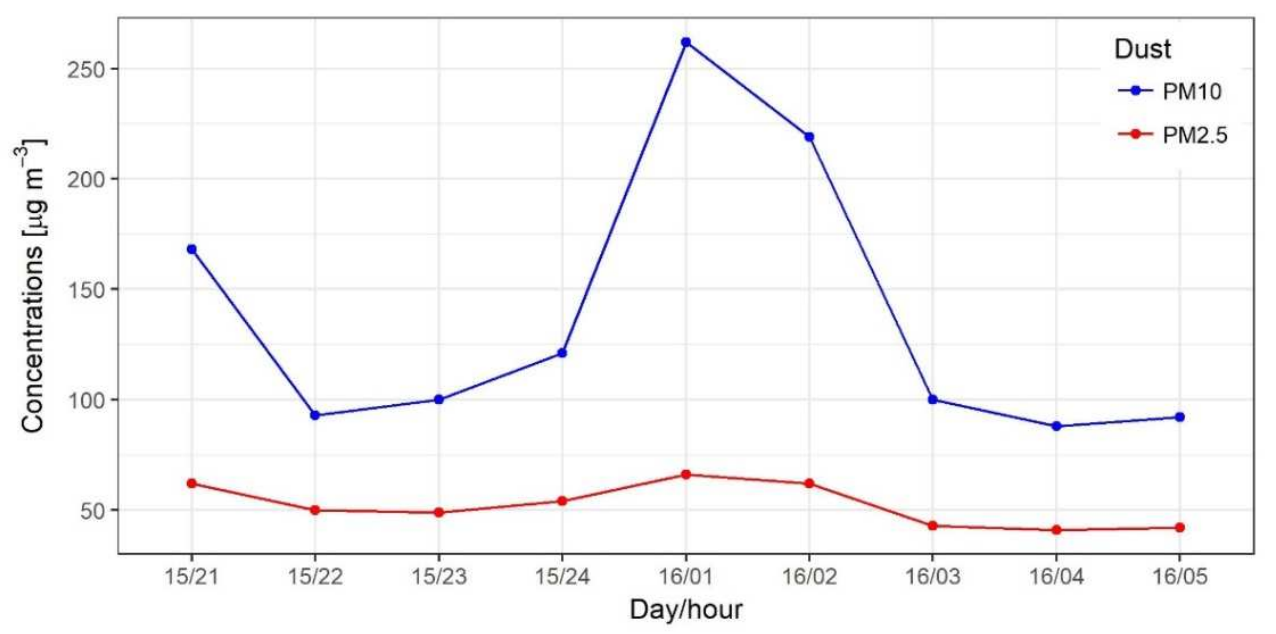

Fig. 1. The episode of the $\mathrm{PM}_{10}$ and $\mathrm{PM}_{2.5}$ concentration increase due to the intensive cleaning of Krasinski avenue recorded at the automatic air quality station located on Krasinski avenue in Krakow.

In Fig. $2 \mathrm{a}$ and Fig. $2 \mathrm{~b}$ the results of a numerical simulation of the $\mathrm{PM}_{10}$ and $\mathrm{PM}_{2.5}$ dispersion in the air are presented, respectively, which resulted from a secondary dust emission on Krasinski avenue caused by its cleaning process.

Presented in Fig. 2a and Fig. 2b, the calculation results indicate, that the highest $\mathrm{PM}_{10}$ and $\mathrm{PM}_{2.5}$ concentrations occur directly above the axes of both roadways, and their value is related to the actual traffic volume and the vehicle structure on both roadways. Within the green belt separating the two roadways a drastic decrease in the level of the 1-hour concentrations of both $\mathrm{PM}_{10}$ and $\mathrm{PM}_{2.5}$ can be noticed. This effect stems from the occurrence of a wind parallel to the road axis during the examined episode (the most frequent wind direction in the street canyon).

In Fig. 2a and Fig. $2 b$ the results of a numerical simulation of the $\mathrm{PM}_{10}$ and $\mathrm{PM}_{2.5}$ dispersion in the air are presented, respectively, which resulted from a secondary dust emission on Krasinski avenue caused by its cleaning process.

Presented in Fig. 2a and Fig. 2b, the calculation results indicate, that the highest $\mathrm{PM}_{10}$ and $\mathrm{PM}_{2.5}$ concentrations occur directly above the axes of both roadways, and their value is related to the actual traffic volume and the vehicle structure on both roadways. Within the green belt separating the two roadways a drastic decrease in the level of the 1-hour concentrations of both $\mathrm{PM}_{10}$ and $\mathrm{PM}_{2.5}$ can be noticed. This effect stems from the occurrence of a wind parallel to the road axis during the examined episode (the most frequent wind direction in the street canyon). 
a)
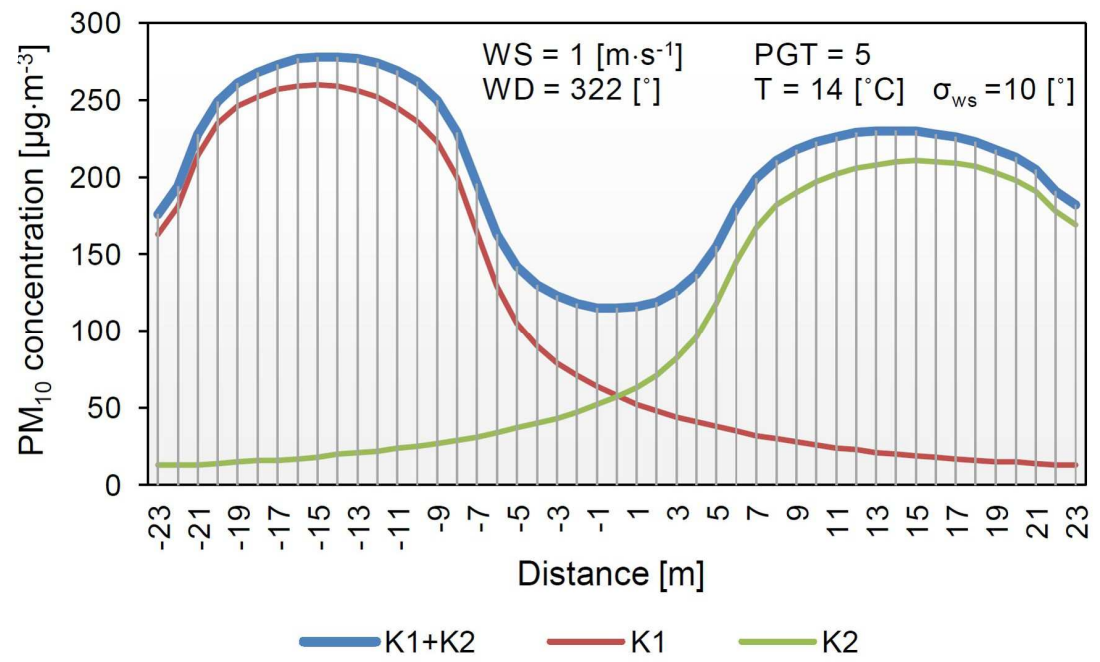

b)
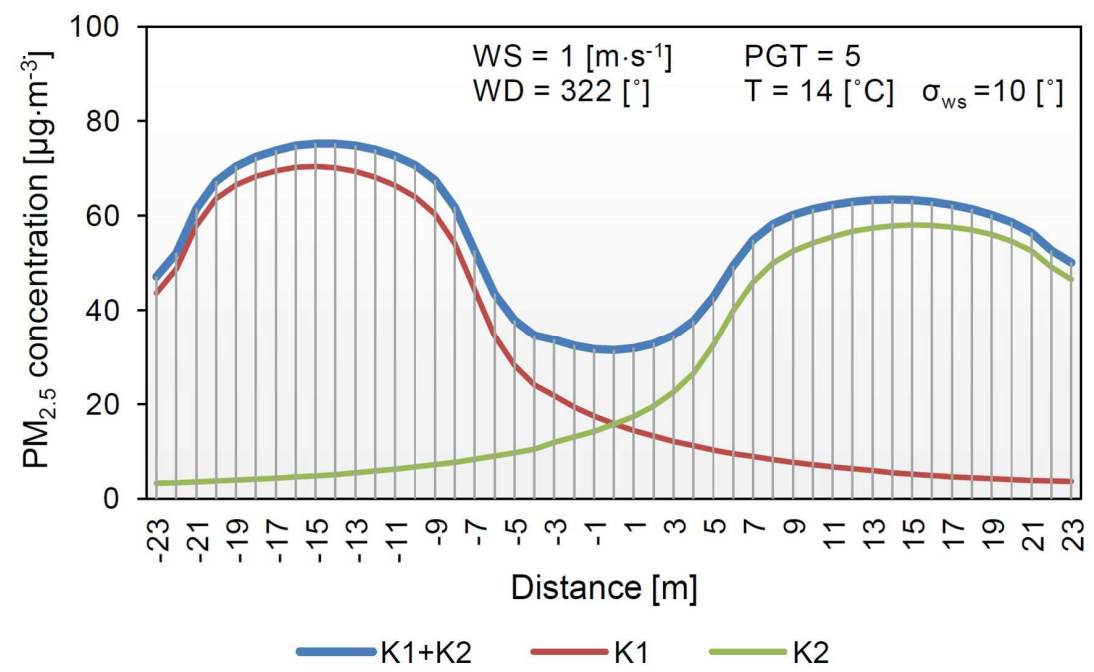

Fig. 2. Calculation results of the $\mathrm{PM}_{10}$ (a) and $\mathrm{PM}_{2.5}$ (b) 1-hour concentrations in the cross-section of the Krasinski street canyon induced by the cleaning process over the night of the $15^{\text {th }}$ to $16^{\text {th }}$ of April 2015 (K1 - left roadway, K2 - right roadway, K1+K2 - total impact of two roadways).

The modelling results of the $\mathrm{PM}_{2.5}$ concentrations in the cross-section of the Krasinski street canyon (Fig. 2b) indicate, that at the location of the automatic air quality station the concentrations of this pollutant caused by the street cleaning may reach the level of $31 \mu \mathrm{g} \cdot \mathrm{m}^{-}$ ${ }^{3}$. However, concentrations of this magnitude are not confirmed by the direct measurements conducted at the air quality station (increase by $12 \mu \mathrm{g} \cdot \mathrm{m}^{-3}$ ). The discrepancy between the $\mathrm{PM}_{2.5}$ observations and the results of model calculations may result from many factors, including: the significant seasonal variation of the fine $\mathrm{PM}_{2.5}$ fraction in the total suspended particulate matter, the possible high elevation of the fine dust above the building height and the transfer of part of the impact outside the street canyon, the potential coagulation of the finest dust fractions as a result of the pavement and roadway washing process, the difficulties associated with the specific behaviour of those particles in the air, the unrepresentativeness of the emission model for the $\mathrm{PM}_{2.5}$ particulate matter fraction, as the relationship between 
the emission rate and the road silt loading (sL) was determined based on the $\mathrm{PM}_{10}$ concentration instead of $\mathrm{PM}_{2.5}$.

The low agreement of the modelling results with the observed $\mathrm{PM}_{2.5}$ concentrations does not influence the fact, that the street cleaning process caused a rapid increase in the $\mathrm{PM}_{10}$ concentrations and a significantly lower one in the case of $\mathrm{PM}_{2.5}$, which lasted for 3 hours and subsequently returned to the pre-cleaning concentrations. Such a scenario of the behaviour of $\mathrm{PM}_{10}$ and $\mathrm{PM}_{2.5}$ concentrations in the air is confirmed by numerous studies conducted in many countries $[2,18,19]$.

\section{Conclusions}

The intensive street cleaning process may contribute to a short-term, lasting up to 3 hours, increase in the air concentrations of $\mathrm{PM}_{10}$ and, to a lesser degree, those of $\mathrm{PM}_{2.5}$ due to the re-entraining process of the dust deposited on the road by the sweeper. The results of modelling calculations confirmed a two-fold increase in the $\mathrm{PM}_{10}$ concentrations measured at the automatic air quality monitoring stations, induced by the mechanical cleaning of Krasinski avenue in Krakow. However, the agreement between the modelling results and the observed values was not achieved in the case of $\mathrm{PM}_{2.5}$, which may be evidence of the model overestimation of this dust fraction for the cleaning episode. The peak concentration of $\mathrm{PM}_{10}$ in the air as a result of the street cleaning diminishes completely in the next 3 hours from the end of the cleaning. The diminishing time is determined to a great extent by the meteorological conditions, in particular wind speed and the atmospheric stability class.

Due to the singular nature of the research, it is impossible to draw the unequivocal conclusions indicating the lack of a reduction of the $\mathrm{PM}_{10}$ and $\mathrm{PM}_{2.5}$ air concentrations in the long period of time after the street cleaning process.

The paper has been prepared within the scope of AGH UST statutory research no. 11.11.150.008.

\section{References}

1. M. Abu-Allaban, John A. Gillies, Alan W. Gertler, R. Clayton, D. Proffitt, Atmos. Environ., 37, 5283 (2003)

2. F. Amato, X. Querol, C. Johansson, C. Nagl, A. Alastuey, Sci. Total. Environ., 408, 3070 (2010)

3. D. de la Paz, R. Borge, M. Vedrenne, J. Lumbreras, F. Amato, A. Karanasiou, E. Boldo, T. Moreno, Front. Environ. Sci., 3, (2015)

4. R. Vautard, B. Bessagnet, M. Chin, L. Menut, Atmos. Environ., 39, 3291 (2005)

5. A. Gruszecka-Kosowska, M. Wdowin, Geology, Geophysics \& Environment, 42, 429 (2016)

6. M. Penkała, P. Ogrodnik, W. Rogula-Kozłowska, Environments, 5, 13 (2017)

7. M. Marjamäki, J. Keskinen, AEAT, Concawe, Volvo, LWA, SU, AT/AUTh, Particulates. Characterisation of exhaust particulate emissions from road vehicles in Deliverable 2: Vehicle exhaust particulates characterisation, properties, instrumentation and sampling requirements (5th Framework Programme. Competitive and Sustainable Growth. Sustainable Mobility and Intermodality. European Commission - DG TrEn, 2001)

8. T. Grigoratos, G. Martini, Non-exhaust traffic related emissions. Brake and tyre wear PM (European Commission Institute of Energy and Transport JRC, (EUR 26648 EN, JRC89231, Luxembourg 2004) 
9. M. Kauhaniemi, J. Kukkonen, J. Harkonen, J. Nikmo, L. Kangas, G. Omstedt, M. Ketzel, A. Kousa, M. Haakana, A. Karppinen, Atmos. Environ., 45, 3646 (2011)

10. M. Rzeszutek, M. Bogacki, P. Bździuch, A. Szulecka, Transp. Res. Part D (2018, in Press, https://doi.org/10.1016/j.trd.2018.04.021)

11. M. Bogacki, M. Mazur, R. Oleniacz, M. Rzeszutek, A. Szulecka, E3S Web of Conferences, 28, 01003 (2018)

12. S. PriyaDarshini, M. Sharma, D. Singh, Atmos. Pollut. Res., 7, 403 (2016)

13. U.S. EPA, AP 42 Fifth Edition, I, 13, Miscellaneous Sources, 13.2.1 Paved Roads (U.S. EPA, 2011)

14. U.S. EPA, AP 42 App. C1, Procedures For Sampling Surface/Bulk Dust Loading (U.S. EPA, 1993)

15. S. B. Fan, G. Tian, S. Y. Cheng, J. P. Qin, J. Environ. Qual., 42, 1039 (2013)

16. I. During, W. Schmidt, VDI, The NORTRIP Model (Non-exhaust road traffic induced particle emission modeling) for the detailed Fine Dust Emission Calculation from Abrasions and Whirling Application Possibilities and Limits, in Diffuse Emissionen, 2017 (VDI-VDE - Verlag Gmbh: Dusseldorf. 2017)

17. F. Barnaba, A. Bolignano, L. Di Liberto, M. Morelli, F. Lucarelli, S. Nava, C. Perrino, S. Canepari, S. Basart, F. Costabile, D. Dionisi, S. Ciampichetti, R. Sozzi, Gian P. Gobbi, Atmos. Environ., 161, 288 (2017)

18. X. Querol (Projekt coordinator), Review of Impact of Street Cleaning on PM10 and PM2.5 Concentrations in Northern and Central Europe in AIRUSE Testing and development of air quality mitigatiom measures in Southern Europe (Report 15, LIIVE 11/ENV/ES/584, 2016)

19. A. Karanasiou, T. Moreno, F. Amato, A. Tobías, E. Boldo, C. Linares, J. Lumbreras, R. Borge, A. Alastuey, X. Querol, Atmos. Environ., 54, 465 (2012)

20. Ch. Yee. Road Surface Pollution and Street Sweeping. Street Sweeping; (https://nature.berkeley.edu/classes/es196/projects/2005final/Yee_C.pdf, acces: April, 20, (2018)

21. Dennis R. Fitz, Kurt Bumiller, J. Air Waste Manage. Assoc., 50, 181 (2000)

22. F. Amato, X. Querol, A. Alastuey, M. Pandolfi, T. Moreno, J. Gracia, P. Rodriguez, Atmos. Environ., 43, 4472 (2009)

23. M. Rzeszutek, M. Bogacki, Rocz. Ochr. Sr., 18, 351 (2016)

24. P. E. Benson, CALINE4 - a dispersion model for predicting air pollutant concentrations near roadways, (California Department of Transportation, Sacramento FHWA/CATL$84 / 15,1989)$ 